\title{
Respiratory symptoms and duration of residence in immigrant teenagers living in Melbourne, Australia
}

\author{
C V E Powell, T M Nolan, J B Carlin, C M Bennett, P D R Johnson
}

\begin{abstract}
Objective-Examination of the relation between respiratory symptoms and time since arrival in Australia in immigrant teenagers living in Melbourne.

Design-Two stage, stratified, cross sectional survey.

Setting-High schools $(\mathrm{n}=51)$.

Subjects-9794 people aged 13-19 years.

Main outcome measures-Prevalence of wheeze during a 12 month period, region of birth, duration of residence in Australia.

Results-The estimated population 12 month period prevalence of wheeze was $18.9 \%$ (95\% confidence interval $(\mathrm{CI}), 18.0$ to 19.9). In subjects born outside Australia, residence for five to nine years in Australia was associated with a 2.1-fold (CI, 1.1 to 4.0 ) increase in the odds of self reported wheeze; after 10-14 years, this risk increased 3.4-fold (CI, 1.8 to 6.7). There was no difference in severity of wheeze, measured by reported frequency of attacks, between Australian born and non-Australian born subjects.

Conclusions-The notion of a continued secular increase in the prevalence of wheezing is not supported. There is a time dose effect on the prevalence of symptoms in subjects born outside Australia and now living in Melbourne, which is independent of age and country of birth.

(Arch Dis Child 1999;81:159-162)
\end{abstract}

Keywords: wheezing; asthma; prevalence; environmental factors

Paired epidemiological studies have suggested that the prevalence of wheezing in childhood has increased. ${ }^{1-3}$ Although some are sceptical about the magnitude or indeed presence of an increase,${ }^{45}$ there is concern among others that the prevalence of wheezing continues to increase. ${ }^{6}$ The likely mechanism for the possible increase is a change in an environmental factor affecting a relatively stable, genetically predisposed population. ${ }^{7}$ Sensitisation to that environmental factor probably occurs antenatally and in the 1 st few years of life..$^{8-10}$

Migrating populations provide the opportunity to observe changes in symptoms with changes in environment and to examine differences in symptoms within a similar environment. The aim of our study was to describe the profile of respiratory symptoms of teenagers living in Melbourne and to examine the effect of region of birth and length of time living in Australia.

\section{Methods}

The study was a cross sectional survey of high school students in the metropolitan area of Melbourne (total population, 3.1 million). Government high schools were included, but independent, non-government schools (which contain $15 \%$ of high school students in Melbourne) were not. A two stage, stratified sampling procedure was used. For the purpose of a related study on the prevalence of tuberculosis infection, ${ }^{11}$ a study group with a high representation of subjects not born in Australia was required. To classify country of birth, the world was divided into 12 geographical regions (table 1). In the first stratum, all schools estimated to have at least $4 \%$ of their population born in any one of these 12 regional groupings (except south east Asia, because a targeted strategy was not necessary to produce sufficient numbers from this region) were selected. In the second stratum (all remaining schools), we selected a 5\% random sample. Within each school, all students at year levels 9 and 10 were invited to participate. The result was a survey based on 50 purpose selected schools with high numbers of overseas born students and an additional seven randomly selected schools.

A research assistant visited the schools and the questionnaire was distributed to all students in the target population. Parents completed the questionnaire. Apart from requesting the student's age, sex, country of birth, and the language spoken at home, the questionnaire asked three questions about wheeze related symptoms and treatment (appendix). These questions were identical to those used in a previous study of Melbourne teenagers. ${ }^{2}$ A complete guide to the questionnaire was available in the 12 most commonly spoken non-English languages.

\section{STATISTICAL ANALYSIS}

The 12 month period prevalence of wheezing or asthma attack was estimated within region of birth with $95 \%$ confidence intervals (CI) obtained using standard methods for proportions. Because the sampling deliberately selected schools with high concentrations of overseas born students, an estimate of overall prevalence of wheezing or asthma attacks was obtained by direct standardisation to the population distribution of region of birth in 12-17 year olds in metropolitan Melbourne

unimelb.edu.au 
Table 1 Distribution of study respondents $(n=9778)$ by region of birth, with 12 month period prevalence of wheeze and $95 \%$ confidence intervals (CI)

\begin{tabular}{lcccl}
\hline Region of birth & Wheeze & Total & Prevalence & 95\% CI \\
\hline Australia & 1282 & 6682 & 19.2 & (18.2 to 20.2) \\
West and North Europe, UK and Ireland, & & & & \\
$\quad$ New Zealand, North America & 51 & 2701 & 8.9 & $(14.4$ to 24.1) \\
Africa & 19 & 1131 & 6.8 & $(10.4$ to 25.0) \\
South East Asia & 34 & 384 & 8.9 & $(6.2$ to 12.1$)$ \\
Southern Europe & 10 & 119 & 8.4 & $(4.1$ to 14.9$)$ \\
South and Central America & 11 & 148 & 7.4 & $(3.8$ to 12.9$)$ \\
Middle East and North Africa & 15 & 208 & 7.2 & $(4.1$ to 11.6$)$ \\
South Asia & 15 & 209 & 7.2 & $(4.1$ to 11.6$)$ \\
Indochina & 54 & 973 & 5.5 & $(4.2$ to 7.2$)$ \\
North East Asia & 14 & 279 & 5.0 & $(2.8$ to 8.3$)$ \\
Oceania & 2 & 64 & 3.1 & $(0.4$ to 10.8$)$ \\
Eastern Europe & 7 & 329 & 2.1 & $(0.9$ to 4.3$)$ \\
\hline
\end{tabular}

(1991 Census data, Australian Bureau of Statistics). Small numbers from each regional group in the stratum of randomly selected schools made it impossible to produce stratum weighted estimates. We compared the prevalence of wheeze in Australian born subjects between the purpose selected and randomly selected schools. Frequencies were compared between region for birth groups, sex groups, and age groups using the $\chi^{2}$ test. For a subgroup of the sample (those included in the subsequent tuberculosis survey), further information was available on length of time since arrival in Australia. Groups were defined reflecting approximate tertiles of time lived in Australia, and wheeze frequency was compared between these. Multiple logistic regression was used to assess the effect of length of time in Australia, adjusting for potential confounding by region of birth and age.

\section{Results}

Of the 57 schools approached to participate, six in the purpose selected stratum declined and one in the randomly selected stratum declined. The latter school was replaced with a geographically neighbouring one, resulting in a study group of 51 schools. The questionnaire was distributed to an estimated 13020 students and $9794(75 \%)$ useable responses were obtained ( $85 \%$ of which were from the purpose selected group), excluding subjects who had a missing date or country of birth or both wheeze and wheeze frequency questions. Subjects were aged between 13 and 19 years; predominantly $14(46.2 \%)$ and $15(38.2 \%)$ years old, and $4569(46.8 \%)$ subjects were boys. No significant difference was found in the 12 month period prevalence of reported wheeze among Australian born subjects in the purpose selected and randomly selected strata $(1028$ of $5428(18.9 \%)$ and 254 of $1254(20.3 \%)$; $\mathrm{p}=0.3$, respectively). For all subsequent

Table 2 Wheeze frequency by time since arrival in Australia, with odds ratio (OR) obtained by logistic regression, both unadjusted and adjusted for age and region of birth $(n=1344)$

\begin{tabular}{lccll}
\hline $\begin{array}{l}\text { Time in } \\
\text { Australia }\end{array}$ & $n$ & $\begin{array}{l}\text { Wheeze } \\
(\%)\end{array}$ & $\begin{array}{l}\text { Crude } \mathrm{OR} \\
(95 \% \mathrm{CI})^{*}\end{array}$ & $\begin{array}{l}\text { Adjusted OR } \\
(95 \% \mathrm{CI})^{*}\end{array}$ \\
\hline 0-4 years & 374 & 3.7 & 1.0 & 1.0 \\
5-9 years & 563 & 7.8 & $\begin{array}{l}2.2 \\
(1.2 \text { to } 4.0)\end{array}$ & $\begin{array}{l}(1.1 \\
(1.1 \text { to } 4.0)\end{array}$ \\
10-14 years & 407 & 12.0 & $\begin{array}{l}3.5 \\
(1.9 \text { to } 6.5)\end{array}$ & $\begin{array}{l}3.4 \\
(1.8 \text { to } 6.7)\end{array}$ \\
\end{tabular}

*Trend test, $\mathrm{p}<0.001$ analyses, the two strata have been combined. Table 1 displays the distribution of subjects and the 12 month period prevalence of wheeze by region of birth.

\section{SYMPTOMS}

The weighted 12 month period prevalence of wheeze or asthma attacks for the whole population was $18.9 \%$ (95\% CI, 18.0 to 19.9 ). There were 9735 subjects who replied to the frequency of wheeze attacks question: $9.2 \%$ (95\% CI, 8.7 to 9.8 ) reported between one and three wheeze attacks; $3.9 \%$ (95\% CI, 3.6 to 4.3) between four and 12 attacks; and $1.9 \%$ $(95 \%$ CI, 1.6 to 2.2$)>12$ attacks each year. There were no significant differences in wheeze prevalence between sex or age groups.

SYMPTOMS AND REGION OF BIRTH

Table 1 shows the 12 month period prevalence of wheeze by region of birth. The prevalence for Australian born subjects $(19.2 \% ; 95 \% \mathrm{CI}$, 18.2 to 20.2 ) was more than twice that among those born outside Australia (8.5\%; 95\% CI, 7.4 to 9.7 ). There was no significant difference in the frequency distribution of wheeze attacks between the two groups $(\mathrm{p}=0.22)$.

SYMPTOMS AND TIME LIVING IN AUSTRALIA

There was a strong trend to a higher 12 month prevalence of wheeze with longer time spent living in Australia $(\mathrm{p}<0.001)$ (table 2). This effect was unaltered by adjustment for age and region of birth.

\section{Discussion}

Different methodology and definitions have hampered the epidemiological study of asthma. ${ }^{12}$ The international study of asthma and allergies in childhood (ISAAC) ${ }^{13}$ has standardised the methodology and a video questionnaire may help with problems of translation and language. ${ }^{14}$ Our study used the same questions as a 1990 Melbourne study, ${ }^{2}$ which reported a 12 month period prevalence of wheezing or asthma attacks ranging from $23.1 \%$ for 7 year olds to $18.6 \%$ for 15 year olds. Our data do not indicate an increase in the 12 month period prevalence of wheeze over the past five years and they do not support the suggestion that the prevalence of respiratory symptoms continues to increase, at least in Melbourne. Aberdeen data, using a three year period prevalence of wheeze, reported a significant increase between 1989 and 1994, from $19.8 \%$ to $25.4 \%$ in $8-13$ year olds. ${ }^{6}$ Comparing these studies illustrates the difficulties of using two different period prevalences as outcome measures. Another study of Australian children aged 13-14 years in 1994-5 found a 12 month period prevalence of wheeze of $29.4 \%$ (95\% CI, 29.1 to 29.7 ), ${ }^{15}$ and these data support the theory of the prevalence increasing. However, the latter study used the ISAAC questions, which were slightly different from the questions used in 1990. Furthermore, in the 1990 study the parents completed the questionnaire, whereas the subjects completed the questionnaire themselves in the larger 1995 ISAAC study. This may be an important factor 
because there are differences between the rates of self reported and parent reported symptoms. ${ }^{16}$ The overall evidence for an increase in prevalence of asthma has been considered weak because the measures used to estimate the prevalence of symptoms are susceptible to systematic errors. ${ }^{5}$ Thus, it is imperative that the same questionnaires and mode of completion are used when comparing repeated studies.

Selection and participation biases might have affected the estimated prevalences. Only $15 \%$ of respondents were randomly selected, but the total sample was drawn from almost one third of Melbourne schools. The $85 \%$ of respondents from schools purposely selected because of their relatively high numbers of overseas born students would not be expected to have different patterns of asthma from those in other schools. This reasonable assumption was supported by our data, which showed no difference in asthma prevalence among Australian born students between the two groups of schools (random and purpose selected). Compared with other studies, ${ }^{23}$ we obtained a lower questionnaire response rate at $75 \%$. Although there are no data to confirm this, it seems unlikely that the likelihood of participation would be strongly related to the presence of wheezing history; however, any such bias might be expected to result in an underestimation of the prevalence of symptoms and the level of treatment. Estimates of population prevalence were standardised to the appropriate distribution of region of birth, thus compensating for the major known bias in sample selection. We did not collect data on smoking and the change in smoking habits over time; some might argue that smoking (active or passive) may be a confounding factor on our conclusions.

The standardised methodology of ISAAC has allowed, for the first time, a comparison of the prevalence of respiratory symptoms from different geographical areas. ${ }^{17}$ Wide variations of symptom prevalence were found: a 12 month period prevalence of wheeze ranging from $1.8 \%$ to $35.3 \%$, with a mean of $14.2 \%$ for 13-14 year olds. ${ }^{17}$ Our data also reveal different prevalences of recent wheeze based on region of birth. The prevalence of wheeze was highest in Australian born subjects and much lower in subjects who were born outside Australia. Making comparisons with studies completed in those countries is difficult because of the methodological problems already alluded to. However, there does appear to be a difference in wheeze prevalence between children from "Westernised countries" and developing countries. ${ }^{18}$

A striking finding of our study is that duration of residence in Australia was strongly associated with reported symptoms. There is a "dose" related response; the longer time spent living in Australia, the more likely the population will adopt the prevalence of the local born population. When controlled for child's age and region of birth the effect remained. This supports the notion that the environment continues to be an important factor in influencing

\section{Appendix}

The three key questions used in this prevalence study:

(1) In the past 12 months has your child had a wheezing or asthma attack? (a) Yes, (b) No

(2) In the past 12 months how frequent were the wheezing or asthma attacks? (a) Less than 4 attacks,

(b) 4-12 attacks,

(c) more than 12 attacks.

(3) In the past 12 months has your child been treated with any of the following medications?

A choice of 10 possible medications: (a) Yes, (b) No, (c) Don't know, for each one.

the prevalence of respiratory symptoms even after the early years of sensitisation. ${ }^{8-10}$ In a contemporaneous study in four Australian states, Robertson et al demonstrated that Australian born subjects were more likely to report current wheeze when compared with those born elsewhere ${ }^{15}$; our data support their findings but add further evidence of a dose time effect. Our study also found that although the prevalence of wheezing varied depending on region of birth, the severity and frequency of attacks were not significantly different between Australian born and non-Australian born subjects. There were no significant differences in the prevalence of symptoms between boys and girls. This peripubertal sex equilibration of the prevalence of wheeze is well known. ${ }^{219}$

Studies using "race" and "ethnicity" as outcome or predicting variables ${ }^{11}$ have problems because of the inherent difficulties of defining those terms..$^{20}{ }^{21}$ We have used "region of birth" as a variable, but this could be criticised because there is evidence of differences between two races from the same geographical region. ${ }^{22}$ It has been suggested that differences in wheeze prevalence in different populations must depend primarily on differences in inherited or acquired hyper-responsiveness and only secondarily on differences in their exposure to environmental factors capable of provoking it. ${ }^{24}$ The dose-time effect that we have demonstrated in subjects living in Melbourne, which is independent of region of birth, would reinforce the strong influence of an environmental factor. Whether this is the "Westernisation factor" suggested by Gregg ${ }^{24}$ and others ${ }^{712}$ cannot be answered by a descriptive study such as ours.

Studies examining the prevalence of respiratory symptoms in migrating populations have yielded conflicting results. In South Africa, Xhosan children living in Transkei had a much lower incidence of exercise induced symptoms compared with children who had moved from Transkei to townships near Capetown. ${ }^{25}$ Leung et al demonstrated large differences between Asian immigrants, Australian born Asians, and non-Asians, with higher levels of reported atopic symptoms in subjects who had been born in Australia compared with those who 
were born outside the country, ${ }^{26}$ and with similar dose-time effects to those found in our study. Tokelauan children who migrated to New Zealand had twice as many asthma symptoms as those who stayed on the island. ${ }^{27}$ Asian children born in Africa have a reported similar prevalence of asthma symptoms to children born in the UK, and it has been postulated that this may be because the lifestyle in Africa is more "Westernised" than it is in the Indian subcontinent. ${ }^{28}$ Children born in Pakistan or India and moving to the UK reported lower symptom rates compared with children born in the UK. ${ }^{29}$ An increase in reported asthma symptoms in Papua New Guinea between 1972 and $1980^{30}{ }^{31}$ was considered to be caused by the introduction of blankets and the house dust mite into the community. ${ }^{32}$ Our data are consistent with the existence of an environmental factor or factors affecting the prevalence of symptoms, independently of genetic susceptibility.

We thank all the families who completed the questionnaire and all the schools who were involved in the coordination of the study.

1 Burr ML, Butland BK, King S, Vaughan Williams E. Changes in asthma prevalence: two surveys 15 years apart. Arch Dis Child 1989;64:1452-6.

2 Robertson CF, Heycock E, Bishop J, Nolan T, Olinsky A, Phelan P. Prevalence of asthma in Melbourne schoolchildren: changes over 26 years. BMF 1991;302: 1116-18.

3 Ninan TK, Russell G. Respiratory symptoms and atopy in Aberdeen schoolchildren: evidence from two surveys 25 Aberdeen schoolchildren: eviden

4 Anderson HR. Is asthma really increasing? Paediatric Respiratory Medicine 1993;2:6-10.

5 Magnus P, Jaakkola JJK. Secular trend in the occurrence of asthma among children and young adults: critical appraisa of repeated cross sectional surveys. BMF 1997;314:1795-9.

6 Omran M, Russell G. Continuing increase in respiratory symptoms and atopy in Aberdeen schoolchildren. $B M Y$ 1996;312:34

7 Seaton A, Godden D, Brown K. Increase in asthma: a more toxic environment or a more susceptible population? Thorax 1994;49:171-4.

8 Holt PG, McMenamin C, Nelson D. Primary sensitisation to inhalant allergens during infancy. Pediatr Allergy Immunol 1990;1:3-13.

9 Miles EA, Warner JA, Lane AC, Jones AC, Colwell BC, Warner JO. Altered T lymphocyte phenotype at birth in babies born to atopic parents. Pediatr Allergy Immunol 1994;5:202-8.
10 Warner JA, Jones AC, Miles EA, Warner JO. Pre-natal sensitisation. Pediatr Allergy Immunol 1996;7(suppl 9):98-101.

11 Johnson PDR, Carlin JB, Bennett CM, et al. The prevalence of infection with Mycobacterium tuberculosis in Melbourne secondary school students. Med F Aust 1998;168: 106-10

12 Nolan T. Asthma. In: Pless IB, ed. Epidemiology of childhood disorders. New York: Oxford University Press, 1994: $415-38$

13 Asher M, Keil U, Anderson $\mathrm{H}$, et al. International study of asthma and allergies in childhood: rationale and methods. Eur Resp F 1995;8:483-91.

14 Crane J. Comparison of findings from the ISAAC written and video questionnaires on asthma symptoms. Eur Respir 1996;9:230s-1s.

15 Robertson CF, Dalton M, Peat J, et al. Asthma and other atopic diseases in Australian children. Australian arm of the international study of asthma and allergy in childhood. Med 7 Aust 1998;168:434-8.

16 Bishop J, Robertson CF, Caust J, et al. Concordance between adolescent and parent response to an asthma morbidity questionnaire. Am Rev Respir Dis 1993;147:A373.

17 Asher M. ISAAC phase one: world-wide variations in the prevalence of wheezing and asthma in children. Eur Respir 1996;9:410s.

18 Sears MR. Descriptive epidemiology of asthma. Lancet 1997;350 (suppl II):1-4.

19 Von Mutius E. Progression of allergy and asthma through childhood to adolescence. Thorax 1996;51(suppl 1):S3-6.

20 Senior PA, Bhopal R. Ethnicity as a variable in epidemiological research. BMF 1994;309:327-30.

21 Bhopal R. Is research into ethnicity and health, racist unsound or important science? BMF 1997;314:1751-6.

22 Mun CT. Pattern of bronchial asthma in Singapore. Singapore Med $\mathcal{f}$ 1972;13:154-60.

23 Ross I. Bronchial asthma in Malaysia. Br F Dis Chest 1984; 78:369-75.

24 Gregg I. Epidemiological research into asthma: the need for broad perspective. Clin Allergy 1986;16:17-23.

25 Van Niekerk CH, Weinberg EG, Shore SC, Heese H de V, Van Schalkwyk DJ. Prevalence of asthma: a comparative study of urban and rural Xhosa children. Clin Allergy 1979; 9:319-24.

26 Leung RC, Carlin JB, Burdon JGW, Czarny D. Asthma, allergy and atopy in Asian immigrants in Melbourne. Med 7 Aust 1994;161:418-25.

27 Waite DA, Eyles EF, Tonkin SL, O'Donnell TV. Asthma prevalence in Tokelauan children in two environments. Clin Allergy 1980;10:71-5.

28 Smith JM. The prevalence of asthma and wheezing in children. Br f Dis Chest 1976;70:73-7.

29 Smith JM. Harding LK, Cumming G. The changing prevalence of asthma in schoolchildren. Clin Allergy 1971;1:5761.

30 Anderson HR, Cunnington AM. House dust mites in the highlands of Papua New Guinea. $P N G \mathrm{Med} f$ 1974;17:304-8.

31 Woolcock AJ, Dowse G, Temple K, Stanley M, Alpers MP. Prevalence of asthma in South Fore people of Papua New Guinea: a method for field studies of bronchial reactivity. Eur F Respir Dis 1983;64:571-81.

32 Dowse GK, Smith D, Turner KL, Alpens MP. The prevalence and features of asthma in a sample survey or urban Goroka, Papua New Guinea. Clin Allergy 1985;15: 429-38. 